\title{
Simultaneous side-by-side bilateral metal stent placement using a colonoscope in a patient with Billroth II reconstruction
}

Bilateral metal stent placement for malignant hilar biliary obstruction (MHBO) can be technically challenging, despite the frequent use of self-expandable metal stents (SEMSs) for palliative therapy $[1,2]$. Simultaneous side-by-side (SBS) stent placement using a thin delivery system is straightforward and has a high success rate [3]. However, simultaneous SBS placement is considered to be technically difficult in patients with surgically altered anatomy because few suitable devices are available. This is the first report of simultaneous SBS stent placement for MHBO using a novel SEMS with a thin delivery system (Zeo Stent V; Zeon Medical, Tokyo, Japan) (\$ Fig.1) and a colonoscope in a patient with surgically altered anatomy.

An 86-year-old man with Billroth II reconstruction was diagnosed with $\mathrm{MHBO}$ caused by unresectable cholangiocarcinoma ( Fig.2a). A CF-260AI colonoscope (Olympus, Tokyo, Japan), which has a 3.7-mm working channel, was used for biliary drainage. Two 0.025inch guidewires (VisiGlide 2; Olympus) were inserted into the intrahepatic bile ducts, and two SEMS delivery systems

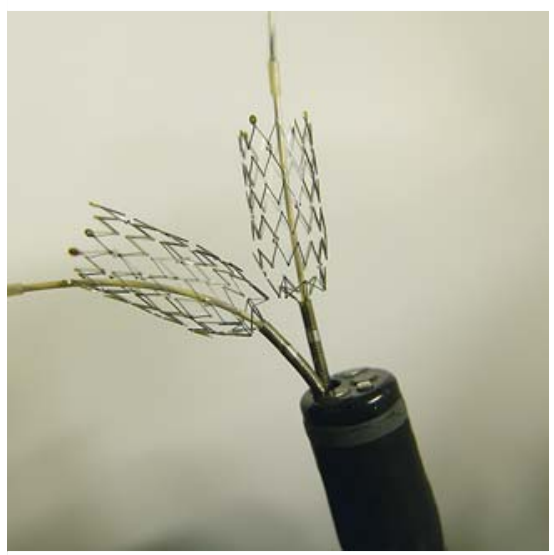

- Fig. 1 The two novel self-expandable metal stents with 5.4-Fr delivery systems (Zeo Stent V; Zeon Medical, Tokyo, Japan) that can be simultaneously inserted into a colonoscope. were simultaneously inserted over the guidewires ( $\triangleright$ Fig. 2 b). We used two novel SEMSs $(8 \times 80 \mathrm{~mm})$ with a $5.4-\mathrm{Fr}$ delivery system (Zeo Stent $V$ ). The two SEMSs were deployed successfully without interfering with each other and were placed in the optimal positions using the SBS technique ( $\triangleright$ Fig. 2 c, d; $>$ Video 1 ). No adverse events were observed and the total procedure time was 9 minutes. Endoscopic bilateral metal stenting is technically challenging $[4,5]$ because of the complexity of the second SEMS insertion. Simultaneous SBS placement avoids the risk of placement failure with the second SEMS. However, few devices are suitable for simultaneous SBS placement in patients with surgically altered anatomy. This combination of a novel SEMS with a 5.4-Fr delivery system and a colonoscope offers the potential for bilateral stenting to treat MHBOs in patients with surgically altered anatomy.

Endoscopy_UCTN_Code_TTT_1AR_2AK

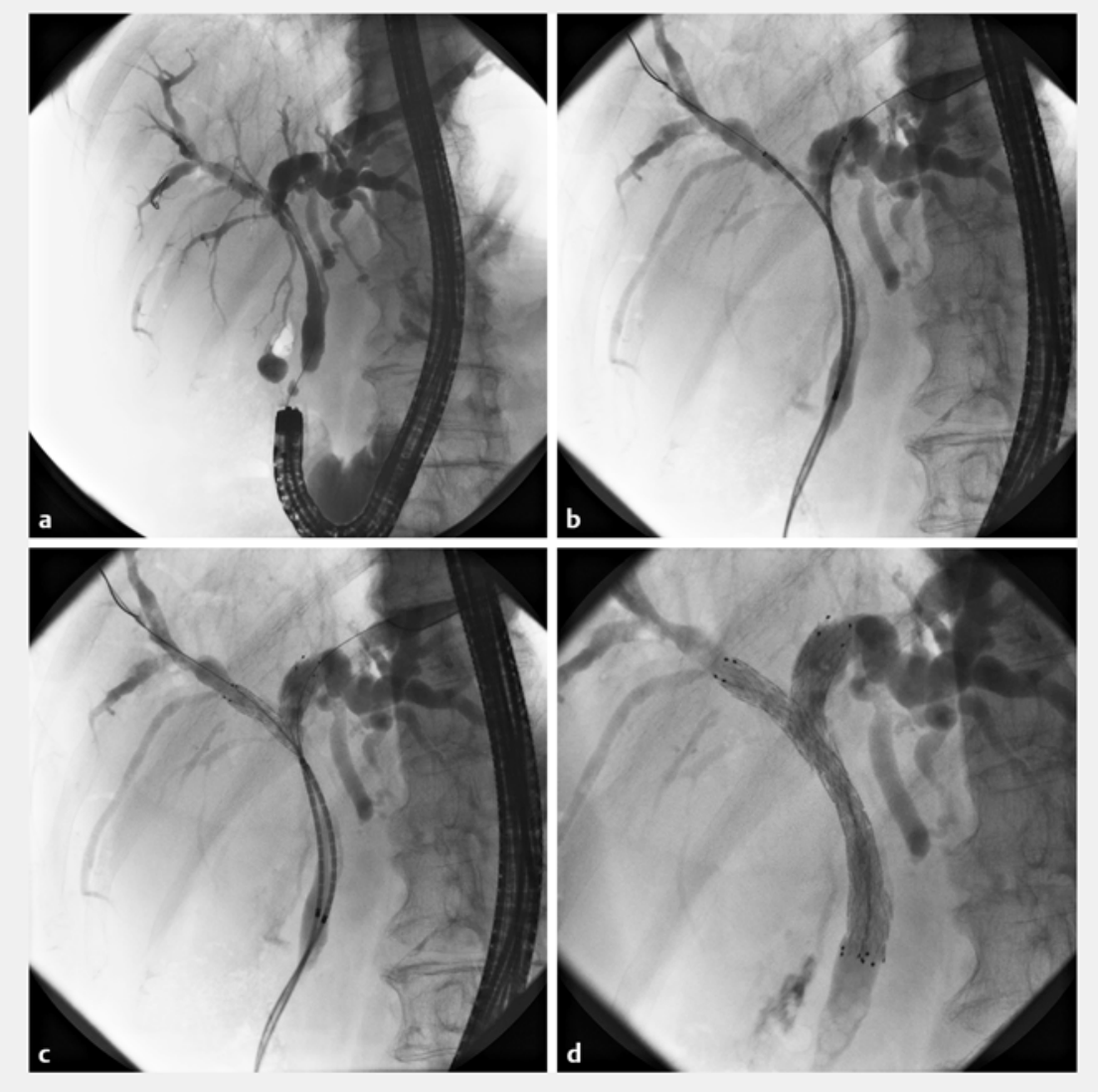

- Fig. 2 Radiographic images from an 86-year-old man showing: a malignant hilar biliary obstructions (Bismuth type IV); b two self-expandable metal stent (SEMS) delivery systems that were simultaneously inserted over the strictures; $c$ two SEMSs after their simultaneous deployment by aligning the distal ends of the delivery systems; $\mathbf{d}$ the two SEMSs successfully placed using the simultaneous side-by-side technique. 


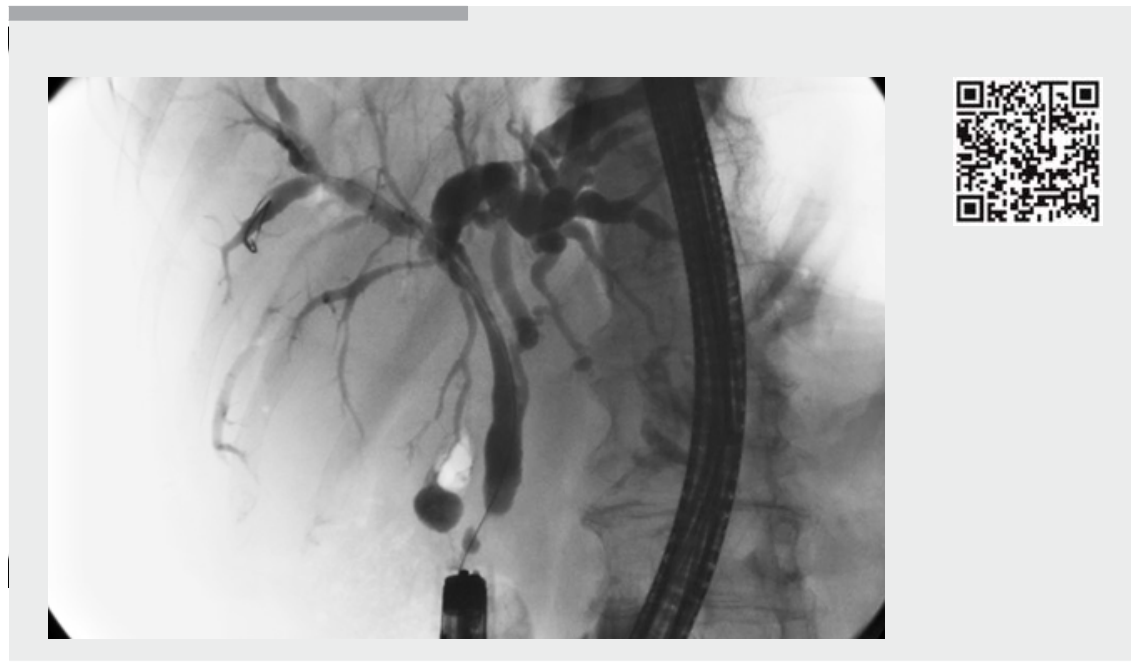

Video 1 Simultaneous side-by-side bilateral metal stent placement for malignant hilar biliary obstruction using a colonoscope in a patient with Billroth II reconstruction.

\section{Competing interests}

None

The authors

Yasuki Hori, Itaru Naitoh, Katsuyuki Miyabe, Michihiro Yoshida, Akihisa Kato, Naruomi Jinno, Kazuki Hayashi

Department of Gastroenterology and Metabolism, Nagoya City University Graduate School of Medical Sciences, Nagoya, Japan

\section{Corresponding author}

\section{Itaru Naitoh, MD, PhD}

Department of Gastroenterology and Metabolism, Nagoya City University Graduate School of Medical Sciences, 1 Kawasumi, Mizuho-cho, Mizuho-ku, Nagoya 467-8601, Japan

Fax: +81-52-8520952

inaito@med.nagoya-cu.ac.jp

\section{References}

[1] Lee TH, Kim TH, Moon JH et al. Bilateral versus unilateral placement of metal stents for inoperable high-grade malignant hilar biliary strictures: a multicenter, prospective, randomized study (with video). Gastrointest Endosc 2017; 86: 817-827
[2] Naitoh I, Hayashi K, Nakazawa T et al. Sideby-side versus stent-in-stent deployment in bilateral endoscopic metal stenting for malignant hilar biliary obstruction. Dig Dis Sci 2012; 57: 3279-3285

[3] Inoue T, Ishii N, Kobayashi Y et al. Simultaneous versus sequential side-by-side bilateral metal stent placement for malignant hilar biliary obstructions. Dig Dis Sci 2017; 62: $2542-2549$

[4] Hori Y, Hayashi K, Yoshida M et al. New concept of traction force applied to biliary selfexpandable metallic stents. Endoscopy 2016; 48: 472-476

[5] Hori Y, Hayashi K, Yoshida M et al. Novel characteristics of traction force in biliary self-expandable metallic stents. Dig Endosc 2017; 29: $347-352$

\section{Bibliography}

DOI https://doi.org/10.1055/a-0624-1947

Published online: 12.6.2018

Endoscopy 2018; 50: E218-E219

(c) Georg Thieme Verlag KG

Stuttgart · New York

ISSN 0013-726X

\section{ENDOSCOPY E-VIDEOS}

https://eref.thieme.de/e-videos

回回 Endoscopy E-Videos is a free

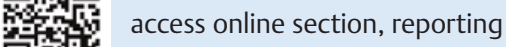
回: on interesting cases and new techniques in gastroenterological endoscopy. All papers include a high quality video and all contributions are freely accessible online.

This section has its own submission website at https://mc.manuscriptcentral.com/e-videos 